\title{
BAD APPLE THEORY OF HUMAN ERROR AND BUILDING INFORMATION MODELLING: A SYSTEMIC MODEL FOR BIM IMPLEMENTATION
}

\author{
Peter E.D. Love ${ }^{1 *}$, David J. Edwards ${ }^{2}$, and $\underline{\text { Sangwon Han }}{ }^{3}$ \\ ${ }^{1}$ Department of Construction Management, Curtin University, Perth, Australia \\ ${ }^{2}$ Business School, Birmingham City University, Perry Barr, UK \\ ${ }^{3}$ School of Civil and Environment Engineering, University of New South Wales, Sydney, Australia \\ * Corresponding author (plove@iinet.net.au)
}

\begin{abstract}
Building information modeling (BIM) is significantly influencing the way in which building and engineering projects are being planned, designed, constructed and maintained. It has been widely advocated that BIM will significantly reduce design and construction errors as well improve project cost and schedule. There is a lack of empirical research about the underlying 'latent conditions' contributing to error, which has resulted in a Bad Apple Theory of human error becoming ingrained within BIM research and practice. Changes to the way BIM is viewed as an error reduction tool are required if it is to significantly improve project performance. The paper proposes a systemic model for BIM implementation so that errors can be reduced. As a result of reducing errors subsequent rework, accidents and failures will also be reduced.
\end{abstract}

Keywords: BIM, Error, Learning, Technology, Software Vendor

\section{INTRODUCTION}

At present there is limited theoretical underpinning as to the causal nature of human errors in design and construction [9]. The suggestion that BIM will reduce human errors during design is therefore misleading, considering the array of exogenous and endogenous variables influencing a designer's cognition and ability to perform tasks [3]. Many design firms, in particular, fail to undertake appropriate design reviews, verifications and audits and as a consequence have limited understanding about errors and their impact on project performance [11]. In fact, most design and construction firms do not quantify the errors they create (and the subsequent rework) [3,11]. Such organizational practices are akin to Bad Apples. Bearing this in mind, how can design professionals and software vendors claim human errors are reduced by implementing BIM? An over-reliance on BIM may simply mask designers' mistakes, miscalculations, and errors of judgment. Decision making due to faulty, incomplete, or imprecise data can only lead to 'garbage in' [2]. The decision-maker is then confronted with a computer-generated BIM and analyses that could be collected and analyzed in no other way. For precisely this reason, going behind the BIM output is out of the question, even if there is a good reason to suspect possible shortcomings [2]. An over-reliance on the output generated by software can have disastrous consequences. For example, the collapse of a Condeep offshore platform, Sleipner A, which resulted in a total financial loss of US\$700 million, was attributed to an over-reliance on computer software [4].

There is a danger that BIM may become 'gospel' and the underlying latent conditions that influence error generation in construction projects are overlooked. A series of new problems may materialize and become intertwined with those that already exist. This may further blur the epistemological and ontological lenses used to examine ways of ameliorating the productivity and performance of construction. In this paper, it is suggested that a Bad Apple Theory of human error prevails within the construction industry. The way in which organizations view and react to errors can influence how effective the uptake of BIM will be. In aiding the uptake of BIM, a systemic framework that 
can be used to proactively reduce errors is propagated.

\section{BAD APPLE THEORY}

A detailed examination of the nature of human error can be found in Reason [17]. Noteworthy, errors are not a cause of an event but a symptom of a much deeper problem within a system [17]. In this paper, the concept of a Bad Apple Theory of human error is used to provide an ameliorated understanding of the environment within which construction organizations operate and why BIM does not reduce errors. A Bad Apple Theory of human error fundamentally assumes that [5]:

- complex systems such as construction projects fail due to the unpredictable behavior of people;

- human errors cause accidents; and

- failures are unexpected.

Research has sought to examine people's experiences and perceptions of design error incidents that occurred in construction projects [11,12]. A review of the responses provided by design consultants revealed that most errors could have been prevented [11,12]. The reasons for errors occurring included: a short-cut was taken and dimensions were not checked; the architect did not provide enough information; and the architect did not pay enough attention to the client's brief. Such perceived design error causes were found to be common, and on face value appear simple to rectify. Such simplicity, however, is misleading. Behind every error event there is often a deeper and more meaningful narrative about the organizational system within which people work. For example:

- new tools and technology can modify error opportunities and pathways to failure [11];

- people reconcile different and often competing goals simultaneously (i.e. profit $\mathrm{v}$ complete documentation) [11,12]; and

- production pressure influences people's trade-offs, making normal or acceptable what was previously irregular or unsafe $[7,11,13]$.
Such narratives are often complex, as the organization and projects within which people work often contain inherent contradictions between efficiency and profit maximization on the one hand, and ethical and professional standards on the other. People working within their organizations learn about the pressures and contradictions, the vulnerabilities and pathways to failure, and subconsciously develop strategies to prevent failures from happening. The developed strategies, however, may not be appropriate and adaptable to circumstances that they may be confronted with. People may focus on the wrong issues and risks. They may be thwarted by their own rules or by the feedback they receive from their managers about what really is important. In fact, strategic decisions taken by managers or decision-makers can provide the latent conditions for errors to materialize. They are essentially decisions and actions that can lay dormant in an organization for a period of time and are revealed by active failures, an error which is precipitated by the commission of errors and violations, which are somewhat akin to 'Bad Apples'. Active failures occur at the point of contact between people and some aspect of a larger system (e.g., a human-machine interface). They are generally readily apparent and almost always involve an operator or someone at the coalface of a task [17].

Unreliable and incompetent staff may cause design errors [9]. In response, managers may endeavor to protect their work environments and professional standards from the vagaries' of human behavior by:

- ensuring unreliable and incompetent staff (i.e. Bad Apples) do not contribute to a task or project by allocating an alternative role, educating or pressuring staff to better perform in the future or instilling fear in them and their peers by reprimanding them;

- tightening procedures and implementing new policies, which reduces the bandwidth in which staff can operate; and

- introducing more technology to monitor or replace human related tasks. 
Adding or enforcing existing procedures does not necessarily guarantee compliance. A typical reaction to errors is procedural over-specification - patching observed holes in an operation with increasingly detailed or tightly targeted rules that respond specifically to the latest incident. But procedural over-specification is likely to widen the gap between procedures and practice, rather than narrow it. New procedures can also get buried in masses of regulatory paperwork.

It is widely assumed that the introduction of BIM will reduce human errors. After all, planning, design, construction and maintenance, as well as whole life cycle costs can be examined in detail. As a result the work previously undertaken individually by project team members is integrated and coordinated; the potential for error is thus perceived to be controlled. BIM technology does not remove errors, but merely relocates, changes or even hides them. What BIM does is to provide practitioners and projects with new capabilities, but it also brings new complexities too, which include:

- an increase in operational demands by allowing projects to be driven faster (i.e. earlier completion may be expected);

- an increased need for coordination and integration and a subtle shift toward using integrated procurement arrangements;

- forcing practitioners to tailor BIM in pragmatic ways to make it work in 'real practice';

- a requirement for people to obtain more knowledge and skills; and

- adding new vulnerabilities that did not exist before. BIM can open new and possibly unprecedented doors to project failures.

New technologies are often used by organizations to reassert their professional status and influence the restructure of organizational forms [16]. Power struggles and shifts between individuals and organizations may often arise over intellectual property, and financial risks associated with the capital investment in hardware and software and that needed to train and maintain technologically skilled staff [8].

\section{BIM SOFTWARE VENDORS}

A number of BIM software vendors such as Autodesk Inc, Bentley Systems Inc, Graphisoft ${ }_{\circledast}$, Nemetschek AG, have their own self interests at heart, as they actively promote the use of their own applications. Software vendors and design consultants who are using BIM claim that it "enhances the quality of the construction documents by reducing human error as well as motivating architects to think through the building process for a more finalized project in the design phase" [1]. This statement is contrary to the findings of both widespread and established empirical research that has examined human error $[7,17]$. Fundamentally, it is impossible to design technological systems to eliminate human errors [6].

There is a hidden danger that practitioners may view BIM as being a 'magic bullet' that can miraculously improve organizational and project performance when gaudy animations and visualizations are used to over-sell the product. Once technology is installed, however, problems may begin to materialize [14]: the promises of BIM may manifest as the organization is forced to comply with the demands of technology. The abundance of Enterprise Resource Planning failures provides convincing testimony of purchasers being swept away by the advertised benefits of implementing software applications espoused by vendors. After all, vendors are selling a product, and make carte blanche promises that may not be achievable to every purchaser [8]. After technology solutions are deployed within an organization, vendors often refer to the process as being a 'death march' [15]. This term describes the upheaval and distress that the technology causes to the organization. Software vendors and their partners will also offer much in the way of assurances about their interest in providing assistant to organization with 'change management' and 'training', but this is inadequate for what is required to attain the benefits that are often espoused. 


\section{SYSTEMIC BIM IMPLEMENTATION MODEL}

It is impossible to design technological systems to eliminate human errors [6]. Systems should therefore be designed that focus on behavior and methods of working during all phases of a project's life cycle so as to reduce opportunities for human error. Figure 1 presents a systemic framework for implementing BIM and reducing and containing errors.

At an organizational and project level a number of key defensive barriers are needed to ensure that erroneous or unsafe acts do not translate into rework, accidents or failures occurring during construction. As denoted in Figure 1, BIM has an important and significant role to play juxtaposed with other activities in containing and reducing errors. Yet, many of the other activities identified, such as error management training, stage gate and project reviews, audits, reviews and verifications are eschewed by design organizations during a project's delivery. Relying solely upon BIM to reduce errors can place considerable liability and strain upon designers, particularly if they do not have the requisite skills and knowledge. Additionally, there is a danger that the designer becomes complacent with the output (as noted above) and fails to check what has been produced, particularly in terms of structural loadings and thermal requirements. Management and organizational decisions are shaped by economic, political and financial constraints: decisions are a compromise.

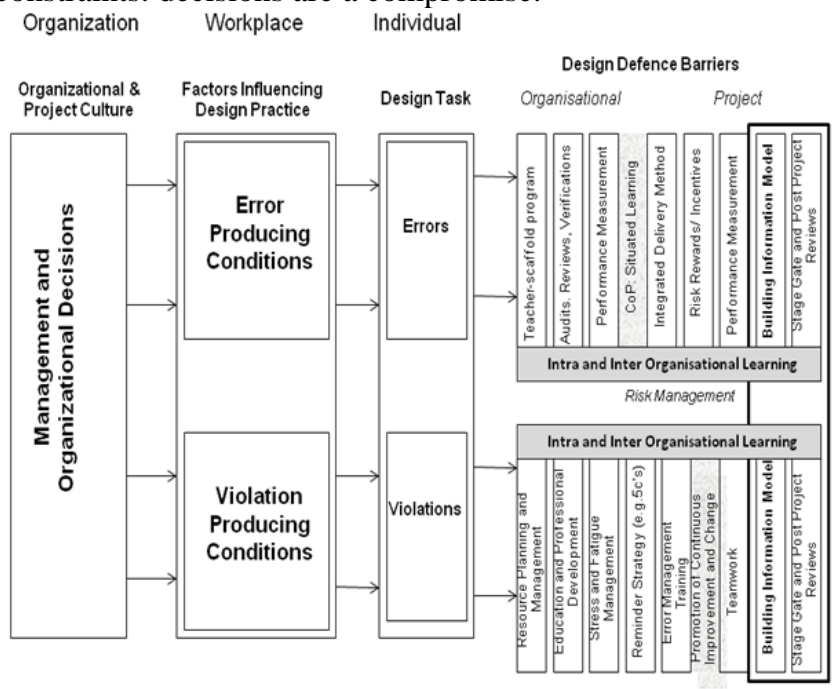

Figure 1. Systemic BIM implementation framework
Therefore, all strategic decisions taken inherently carry some negative consequences. For example, if a design firm decides to accept a low fee for their services (latent condition), this may result in some tasks being omitted for example, design checks and reviews. Consequently, the likelihood that design errors and rework will materialize during construction increases. Not all decisions are flawed, but decisions judged at the time as being sound may entail a probable downside for an individual at some point during a project's lifecycle. Resources, for example, are rarely allocated evenly within design and construction organizations as projects face different challenges, needs and priorities. Unfortunately, some projects may be under resourced. In judging uncertainty during the design and construction of a project, some decisions taken by managers will be inexorably erroneous. The creation of latent failures cannot be prevented, but their adverse consequences can be made visible before they combine with local triggers, that is, atypical conditions that can create failures, to contravene the defenses that are put in place. Many of these strategies have been identified as enablers for improving individual, organizational and project performance. For example, 'Communities of Practice' can be used to share experiences and knowledge so that new approaches to problems can be fostered [10]. In particular, the situated practice that people are exposed to can be utilized as a rich source of knowledge formation.

The key to effective error management in construction projects is to target what are invariably limited remedial resources at the most tractable problems: in short, to manage the manageable. In most organizations a disproportionate amount of these resources is directed at individual practice in an effort to prevent the recurrence of past errors through the provision of training. These measures are only appropriate if the people who commit the active failures are particularly error-prone, inexperienced, poorly motivated and trained. The psychological antecedents of error are extremely difficult to control. Distraction, momentary inattention, lapses, preoccupation and fixation are natural human reactions that 
may often confront designers on a daily basis. This then makes them prone to committing errors, even when using BIM. A reminder strategy can be used to aid memory lapses that may arise during times of schedule pressure and high workload [9]. Examples of reminders include: post-it notes, diaries, creating lists of things to do, object positioning, getting others to remind them, and mental checking.

Active failures that are committed by designers are unpredictable in their precise details and therefore difficult to manage. As noted above, latent failures exist within the context of the task to be undertaken, the organization and project; they are present before the occurrence of any incident or mishap. As they are the precursors of error they represent the most suitable issues to address. Latent failures need to be addressed at an organizational and project level if BIM is to be effectively implemented, as errors can potentially be embedded into the information and actions that are used to construct a model. It is important that risk management, performance measurement and inter and intra organizational learning are continuously undertaken to ensure error inputs are minimized. It is only through measuring errors and implementing strategies to reduce their occurrence, for example, stage gate reviews and post project reviews that can stimulate inter and intra organizational learning to take place. Learning should be integrated with a risk management strategy so that errors and rework are managed accordingly. The use of integrated project delivery methods is pivotal for BIM implementation. There also needs to be an incentive for organizations to reduce errors and rework. If error reduction is identified as a key performance indicator by clients, and financial incentives are offered to produce contract documentation that is of a high quality, then the incidence of errors may be significantly reduced. While BIM can be used to improve the quality of documentation produced, mitigate clashes, and reduce the incidence of design changes through visualization, it cannot eliminate human error and the latent conditions that evoke their occurrence. Software vendors and practitioners need to ensure that appropriate systemic conditions are in place prior to using BIM.

\section{CONCLUSION}

Many practitioners and software vendors have advocated that BIM can significantly reduce the amount of design errors that occur in construction and engineering projects. To date there has been limited empirical research on error causation in construction. There is a danger that if BIM becomes the sole driver for error containment and reduction latent failures will become deeply embedded within the organizational and project related processes and hinder long term efforts to ameliorate the performance and productivity of the construction industry. An array of error strategies need to work together in unison to prevent errors from arising during design. Once errors are identified there is a degree of rework which can adversely influence project performance. BIM will significantly improve the performance of projects, if it is used as an enabler juxtaposed with other key strategic and process innovations that have been identified. If not, then it will not be the panacea that software vendors and many practitioners advocate it to be. Until systemic approaches to error reduction are undertaken, it is suggested that organizations err on the side of caution with regard to BIM, as garbage in may lead to gospel out, with the resultant benefits not materializing as expected.

\section{REFERENCES}

[1] Applied Software, "FreemanWhite inspires communication and design centric philosophy through BIM business solution from Applied Software” (Accessed $23^{\text {rd }}$ July 2010 at www. http://www.asti.com/Clients/FreemanWhite)

[2] Brooks, D.T., Becker, B., and Marlatt, J.R. “Computer applications in particular industries: securities”. In Computers and The Law, American Bar Association, Section of Science and Technology, Third Edition, 1981

[3] Busby, J.S., "Error and distributed cognition in design”. Design Studies, Vol. 22, pp.233-254, 2001

[4] Collins, M.P., Vecchio, F.J., Selby, R.G., and Gupta, P.R., "Failure of an offshore platform". Canadian Consulting Engineer, March/April, pp.43-48, 2000

[5] Dekker, S. “The Field Guide to Understanding Human 
Error”, Ashgate, UK, 2006

[6] Foord, A.G., and Gulland, W.G., "Can technology eliminate human error? Process Safety and Environmental Protection, Transactions of the Institute of Chemical Engineers, Part B, Vol. 84(B3), pp.171-, 173, 2006

[7] Goh, Y., Love, P.E.D. Sprickett, J., and Brown, H. "Organizational accidents: A systemic model of production versus protection”. Journal of Management Studies, in press, 2011

[8] Irani, Z., and Love, P.E.D., "The propagation of technology management taxonomies for evaluating information systems, Journal of Management Information Systems , Vol.7(3), pp.161-177, 2000

[9] Lopez, R., Love, P.E.D., Edwards, D.J., and Davis, P.R. "Design error classification, causation and prevention for constructed facilities”, ASCE Journal of Performance of Constructed Facilities, Vol. 24(4), pp. 399-408, 2010

[10] Love, P.E.D. “Communities and champions of practice: Catalysts for learning and knowing”, Construction Innovation, Vol. 9(4), pp. 365 - 371, 2009

[11] Love, P.E.D., Irani, Z and Edwards, D., ”Learning to reduce rework in projects: Analysis of firms learning and quality practices”, Project Management Journal Vol. 34(3) pp.13-25, 2003

[12] Love, P.E.D., Edwards, D.J., Irani. Z., and Walker, D.H.T., "Project pathogens: The anatomy of omission errors in construction and resource engineering projects", IEEE Transactions on Engineering Management Vol. 56(3), pp.425-435, 2009

[13] Love, P.E.D., Lopez, R. Edwards, D.J. and Goh, Y. "Systemic modeling of design errors in social infrastructure projects”, Accident Analysis and Prevention In press, 2011

[14] Markus, L., M., and Benjamin, R.I., "The magic bullet theory in IT-enabled transformation”, Sloan Management Review, Winter, pp.55-68, 1997

[15] McKnight, R. "How to avoid the ERP blues: Advice for executives who are leading IT-drive change"., Profit Point Inc (Accessed $23^{\text {rd }}$ July 2010, www.profitpt.com)

[16] Orlikowski, W.J., "Using technology and constituting structures: a practice lens for studying technology in organizations”, Organization Science, Vol. 11(4), pp.404-
428, 2000

[17] Reason, J.T., “Human Error”, Cambridge University Press, Cambridge, 1990. 